\section{ENTRE PERCEPÇÃO, HISTORICIDADE E EXPRESSÃO: A DANÇA COMO LINGUAGEM}

\author{
AMONG PERCEPTION, HISTORICITY AND EXPRESSION: DANCE AS A \\ LANGUAGE P्?
}

ENTRE PERCEPCIÓN, HISTORICIDAD Y EXPRESIÓN: LA DANZA COMO LENGUAJE C

doi) https://doi.org/10.22456/1982-8918.103309

Danieli Alves Pereira Marques* <edf.danieli@gmail.com>

Elenor Kunz** <elenkunz@terra.com.br>

\begin{abstract}
*Universidade Federal dos Vales do Jequitinhonha e Mucuri. Diamantina, MG, Brasil.

**Universidade Federal de Santa Catarina. Florianópolis, SC, Brasil.
\end{abstract}

Resumo: Este ensaio, à luz das reflexões filosóficas de Merleau-Ponty, almeja compreender a dança como linguagem. É a partir da correlação entre percepção, historicidade e expressão que o filósofo visualiza proximidades entre arte e linguagem. Para compreender a conexão desses três elementos, situamos alguns acontecimentos no processo de desenvolvimento da dança ao logo do tempo, trazendo trabalhos de artistas da dança moderna e contemporânea. Trata-se de condição importante para percebemos que a dança nunca deixa de se transformar. Tal proposição nos faz compreender como as expressões não estão alheias ao tempo e se alimentam de suas próprias mobilidades. É pelos entrecruzamentos perceptivos que a expressão nunca conhece o fim, nunca se completa, havendo sempre mais por dançar. Abrir-se para a linguagem como realização de sentido, experiência de mundo, é fundamental para pensarmos possibilidades da experiência da dança como linguagem.

Palavras chave: Dança. Linguagem. Filosofia. Percepção.
Recebido em: 22-05-2020 Aprovado em: 01-12-2020 Publicado em: 29-12-2020

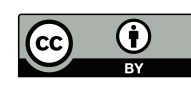

Este é um artigo publicado sob a licença Creative Commons Atribuição 4.0 Internacional (CC BY 4.0).

eISSN: $1982-8918$ 


\section{INTRODUÇÃO}

O desejo de compreender as possibilidades da dança como linguagem move esta investigação. Isso se deu pelo fato de termos nos deparado, ao longo do percurso reflexivo, com muitas suspeitas e questionamentos em relação a tal expectativa, já que, comumente, a linguagem é pensada como operação do intelecto, conservatória de significações fixas, suporte para acomodação de sentidos claros e precisos. Inspirados na abordagem filosófica de Merleau-Ponty ${ }^{1}$, sobre uma linguagem de caráter não instrumental, buscamos outras possibilidades interpretativas. Reiteramos, no entanto, que não se trata de reduzir o movimento à palavra ou vice-versa, mas, sim, buscar aproximações em seus modos de ser, em suas forças criadoras, geradoras de sentido e, com isso, compreender, aos poucos, por que Merleau-Ponty tanto aproximou a expressão por palavras das demais formas expressivas.

É a partir da correlação entre percepção, historicidade e expressão que Merleau-Ponty visualiza proximidades entre arte e linguagem. Tal proposição nos faz compreender como as expressões não estão alheias ao tempo e se alimentam de suas próprias mobilidades. Para compreender a conexão desses três elementos, situamos alguns acontecimentos no processo de desenvolvimento da dança ao logo do tempo, trazendo trabalhos de artistas da dança moderna e contemporânea. Trata-se de condição importante para percebermos que a dança nunca deixa de se transformar.

Palavras e movimentos não se restringem a um sentido acostumado, mas abrem um campo de significações, uma busca, cujos sentidos nunca terminamos de desenvolver. Pelos entrecruzamentos perceptivos, temos tempos em abertura e, não havendo rivalidade entre suas dimensões (passado-presente-futuro), há continuidade; recomeço pela diferença, já que a expressão nunca conhece o fim, nunca se completa, havendo sempre mais por dançar.

\section{LINGUAGEM: A EXPERIÊNCIA DA EXPRESSÃO}

Merleau-Ponty, ao apresentar o problema da linguagem em Fenomenologia da Percepção (1999), atesta o parentesco entre as concepções empiristas e intelectualistas quando tratam dessa temática. Para essas abordagens, a linguagem é apenas um invólucro vazio, causalidade objetiva, acompanhamento exterior do pensamento.

Confirma o filósofo: é preciso rever as teorias que permitem conceber entre pensamento e fala apenas relações de exterioridade. A linguagem não reproduz pensamentos, eles já estão totalmente envolvidos nela. Logo, a linguagem não os traduz, mas antes os apresenta, pois se trata de uma tomada de posição do sujeito no mundo. Portanto, busca-se ultrapassar tais concepções pela simples observação

1 Filósofo francês considerado um dos representantes da fenomenologia. Foi influenciado por filósofos contemporâneos franceses, tais como Henri Bergson e Gabriel Marcel. Mas, a influência mais significativa foi a do movimento fenomenológico iniciado por Edmund Husserl. Da fenomenologia da consciência à fenomenologia da percepção, Merleau-Ponty dá espaço aos estudos do corpo, reconhecendo que o conhecimento se dá a partir das relações vivas da experiência corporal (MATTHEWS, 2010). Dessa forma, influencia filósofos como Michel Foucault, Gilles Deleuze e Félix Guattari. 
- a palavra tem sentido. Como nos mostra Merleau-Ponty (1999, p. 247), longe de ser simples signo dos objetos, do pensamento e das significações, a palavra habita as coisas e veicula as significações, "o sentido está enraizado na fala".

Temos sempre a ideia de que a linguagem articulada, escrita ou falada, diferencia-se das demais formas expressivas, justamente porque sua objetividade nos permite sermos mais precisos; imaginamos, ou temos a ilusão de que as palavras aprisionam significados e tudo dizem. Mas, como insiste Merleau-Ponty (1991, p.44) em nos alertar, "a relação do sentido com a palavra já não pode ser essa correspondência ponto por ponto que sempre temos em vista". Ora, diz o filósofo, é preciso eliminar a ideia da existência de um texto original, do qual nossa linguagem seria simplesmente a tradução ou a versão cifrada, pois, ao dizermos algo, também deixamos de dizer, nunca concluímos a expressão, ela jamais se completa. Se pararmos para observar, presenciamos que toda linguagem é indireta e se preferirmos: silêncio.

Em uma de suas notas de O Visível e o Invisível (2007), Merleau-Ponty afirmará que, como toda práxis, a linguagem supõe um instituído, uma fundação, que nos prepara para outra. Há uma comunidade sucessiva e simultânea de sujeitos falantes que nos permitem tomar posse, através do querer, do falar e, finalmente, do pensar.

Mas de que maneira as significações estão disponíveis? - indaga-se MerleauPonty (1991). Essas surgiram por uma operação expressiva da mesma espécie, foram instituintes ao seu tempo e entrando para a tradição somos nós todos seus herdeiros. A expressão ocorre quando nos instalamos na linguagem já falante (fala falada) e com ela deslizamos dos sinais ao sentido, fazendo-a dizer novamente o que nunca havia dito (fala falante) (MERLEAU-PONTY, 1991, 1974).

Uma vez que não recorremos à tradição como se fosse um objeto dado, nela e com ela nos transfiguramos, reconfigurando, ao nosso tempo, uma nova significação. O livro, uma vez produzido, permanece acrescentado na herança cultural, mas no momento da leitura a expressão passa a tomar posse do leitor. É verdade que o leitor carrega consigo um conjunto de significações já disponíveis (linguagem falada), sem as quais não seria possível iniciar a sua leitura. No entanto, ao iniciá-la, instaura-se um diálogo e, por sua vez, uma nova interpretação tende a aparecer (linguagem falante) (MERLEAU-PONTY, 1974). Eis a virtude da expressão, e não teremos nunca a ideia do seu poder, acrescenta Merleau-Ponty,

[...] enquanto não se tiver reconhecido essa linguagem operante ou constituinte que aparece quando a linguagem constituída, repentinamente descentra e privada de seu equilíbrio, ordena-se novamente para ensinar ao leitor - e mesmo ao autor - o que ele não sabia pensar ou dizer (MERLEAU-PONTY, 1974, p.30).

A linguagem se faz germinar no próprio corpo e somos nós seres imperfeitos que sustentamos a linguagem e se, por vezes, Merleau-Ponty fez críticas às teorias empírico-analíticas, para afirmar a existência corporal não como objeto, mas como vivacidade orgânica, comparando-a à obra de arte, o mesmo ocorre com a linguagem. Não se trata de falar de linguística, mas o que para muitos podemos chamar de experiência da linguagem ou experiência da expressão. 
Tanto a existência da palavra quanto a do movimento humano estão condicionadas à experiência da expressão encarnada, necessitando "vir ao gesto", sempre a cada vez. Na imperfeição, ou impermanência da vida expressiva mora justamente a potência do corpo, de não permitir que a expressão seja cópia de algo dado; ela sempre difere de si mesma; o corpo trai a originalidade de qualquer cultura (BERNARD, 2001), é expressão em ato com sentidos agidos.

Para Merleau-Ponty, as palavras nada mais são do que o resultado desse encontro entre ser e mundo; por isso, antes de tornarem-se instrumento na ciência da linguagem, antes de pertencerem ao dicionário, elas pertencem à experiência do gesto encarnado, linguagem falante, que agrega um devir com fissuras. Por isso, Merleau-Ponty falará não de uma representação da linguagem, mas de uma potência da expressão, criadora, que deveria ser aproximada das outras artes da expressão, porque a linguagem expressa justamente aquilo que ali está a acontecer.

Isso é o que nos diz Dantas (1999), quando salienta que os sentidos, quando instaurados pelos movimentos dos bailarinos, assumem um caráter ambíguo, uma vez que a dança não reproduz, mas cria sentidos e, por esse motivo, a ambiguidade perpassa, tanto a obra como o espectador que se põe a deslizar em sentidos plurais. Então, o importante "não é perguntar o que a dança tem a dizer, mas sim especular a respeito de como o movimento, em dança, adquire sentido, buscando-o no corpo e no movimento" (DANTAS, 1999, p. 61). Esse é o ponto de chegada de Gil (2004, p.78) quando, tantas vezes, recorre aos pensamentos de Merce Cunningham ${ }^{2}$ para dizer que "no movimento dançado o sentido torna-se ação". De forma semelhante, ainda conferimos com Godard que "é no gesto que a produção de sentido se organiza" (GODARD, 2001, p. 32), uma vez que as variações mínimas da parte do corpo que iniciam o movimento, os fluxos de intensidade, a maneira singular que cada dançarino possui, de antecipar e visualizar o movimento que produz, fazem com que a mesma figura, ou a mesma dança, não se detenha na produção do mesmo sentido (GODARD, 2001). Fazendo uso da expressão de Gadamer (2012), assim como um texto, a dança não se limita a dizer sempre o mesmo, mas para quem a interroga dá novas respostas, e a quem lhe propõe respostas sempre apresentará novas perguntas. Uma travessia de experiências, como assinala Louppe (2012), que marca o nascimento de estesias, num encontro que provoca a experiência da percepção, no tempo e no espaço. Por isso, a dança, assim como qualquer outro gesto, nos lança para além daquilo que exprimimos.

Se os sentidos dos gestos, sejam eles quais forem, os habitam no movimento da expressão, podemos anunciar que a dança, transbordando em nós, é semelhante à chuva que cai; os sentidos nos invadem, como a água que escoa na terra, nela penetra, e faz ali germinar vida própria, vida que não se fecha em si mesma, lançase para além dela, dá vida a outras vidas. Gestos calorosos, em estado vivo, brotam sentidos em nossa carne que, no entanto, não se aprisionam; somos solo fértil, fazendo da dança um eterno nascer em nós e no outro. Com isso, se nos embaralhamos ao pensamento de Fensterseifer (2004), aceitamos que, "enquanto uma palavra estiver presente na linguagem [e enquanto um movimento estiver presente na dança], seus

2 Bailarino e coreógrafo norte-americano, um dos representantes da contemporaneidade na dança. 
sentidos estão abertos" e, portanto, "cabe a nós a produção de novos sentidos, possibilidade que deriva da 'imperfeição' das palavras [e dos movimentos], que tal como a vida, não é precisa" (frases em itálico nossas).

Palavras e movimentos, para além das particularidades, guardam cumplicidades, quando entendemos, com Fensterseifer e Pich (2012), ser a linguagem o próprio modo pelo qual o ser se dá, ou seja, experiência de mundo, na qual o ser humano é capaz de diversas linguagens, em constante vir a ser.

\section{O CAMPO DE SIGNIFICAÇÕES NA DANÇA: O INACABAMENTO DA EXPRESSÃO}

Visando entender a dança como linguagem, nessa perspectiva de ser-nomundo, recorremos às reflexões edificadas por Merleau-Ponty no texto $A$ linguagem indireta e as vozes do silêncio ${ }^{3}$. Nesse escrito, Merleau-Ponty entrelaça discussões sobre a experiência da linguagem e a experiência pictorial, apontando-nos caminhos para, então, observarmos, como é legitimo tratar a pintura como linguagem, sem esquecer que a pintura se expressa a seu modo, o que não inviabiliza a possibilidade de tratar ambas como gesto, experiência corporal no mundo, uma trama envolvida e envolvente, entre eu-outro-mundo. Isso só é possível, segundo o filósofo, se nos voltarmos para a correlação de três elementos, ou problemas: Percepção, História, Expressão. Da rotação cambiante causada pelo imbricamento desses três elementos, ou mais que elementos, surge a possibilidade de compreendermos através da experiência da arte e da linguagem como se dá a percepção de outrem e o diálogo, ações que sustentam o aparecimento da expressão junto ao partilhamento do mundo, relações que nos transformam e que transformamos, marcadas sempre por uma temporalidade que em nós se funde. Ainda nos alerta Merleau-Ponty que, por certo, pelo exemplo das artes e da linguagem, poderemos reencontrar o conceito de história em seu verdadeiro sentido.

Merleau-Ponty (2004) quer nos mostrar uma historicidade operante que percorre o campo de significações no universo da pintura, e que pode ser comparada ao nosso corpo como um todo, já que não há separação entre suas partes, elas estão todas implicadas umas às outras, reunidas por um motivo central - o aparecimento da expressão. Contudo, quer eliminar a ideia de uma história que se encerra em algum ponto, ou que possa ser dividida em acontecimentos sucessivos. Ao interrogar-se sobre semelhanças encontradas em obras de diversos cantos no mundo, MerleauPonty, aponta que esse fenômeno não poderá ser compreendido, se "começamos por nos colocar no mundo geográfico ou físico, e por colocar aí as obras, como eventos separados cuja semelhança ou simples parentesco fica então improvável e exige um princípio de explicação" (MERLEAU-PONTY, 2004, p. 100).

Para tal, o que se propõe é o direcionamento do olhar para a cultura a partir de uma ordem geral do advento. Com a expressão advento, o filósofo quer sinalizar que a cultura não deriva de eventos puros, não consiste em um evento fechado em sua 
diferença, e muito menos se encontra terminada de uma vez por todas. Advento indica inauguração de sentidos, sequências ou recomeços. Esse é o excesso encontrado nas obras que ultrapassam o espaço e o tempo, e que não poderá ser compreendido se pensarmos em um mundo fragmentado ${ }^{4}$.

Trata-se de reconhecer aqui uma história cumulativa, "que prossegue em cada pintor que reanima, retoma, e relança a cada nova obra o empreendimento inteiro da pintura" (MERLEAU-PONTY, 2004, p. 92). Isso nos ajuda a reconhecer a criação na arte, não como um milagre, mas, sim, encontro com o mundo, o que levará MerleauPonty em uma das notas de trabalho de O visível e o invisível, sublinhar que a criação apenas do ponto de vista natural é insuficiente, "[...] trata-se de uma criação que é invocada e engendrada pelo Lebenswelt como historicidade operante, latente, que a prolonga e dela dá testemunho" (MERLEAU-PONTY, 2007, p. 170).

Se começamos a transpor tais reflexões para o universo da dança, vemos que sua história no ocidente tradicionalmente demarca bem as fronteiras de um acontecimento ao outro, classificando-os, apresentando-os como fatos cronológicos. Ao contrário, o que Merleau-Ponty (2004) quer nos mostrar é que, se pensamos a historicidade a partir da ordem do advento, muito mais que simples fronteiras, há superfície de contato, diálogo, que se dá porque somos seres encarnados. O corpo aqui é reconhecido como um sistema voltado à inspeção do mundo, sua capacidade transpõe distâncias e desvenda o futuro perceptivo.

As obras de arte não mostram claramente os processos pelos quais passaram para chegar à visibilidade, por isso há sempre um fundo invisível sustentando o aparecimento da expressão. É o que sinaliza Louppe na obra Poética da dança contemporânea, quando rejeita a concepção linear da história da dança e se interessa, como ressalta Fazenda (2012, p. 9), pela "profundidade que urge procurar a dimensão invisível dos acontecimentos, lá onde as relações se tecem, onde as práticas se modificam e as variantes individuais nascem, e de onde emergem as novas complexidades".

Nossas percepções se entrecruzam, e são partilháveis graças à nossa capacidade de ser, e se dar como linguagem.

Se suscitarmos essa relação mais profunda do aparecimento da expressão, observamos que não há como fugir do mundo para dançar, para estarmos situados na tradição, ou no universo dançante; basta dançarmos, e fazemos isso muitas vezes sem ter consciência de que estamos retomando algo que aqui já se manifestava. A tradição não é algo que nos é distante, mas sim uma espessura, da qual já estamos impregnados.

Assim, assinala Merleau-Ponty (2004, p. 103) que

[...] a quase-eternidade da arte se confunde com a quase-eternidade da existência encarnada, e temos no exercício do nosso corpo e de nossos sentidos, na medida em que nos inserem no mundo, os meios de compreender nossa gesticulação cultural, na medida em que esta nos insere na história.

\footnotetext{
4 Merleau-Ponty assinala que, assim como é preciso pensar o mundo para além do ponto de vista geográfico ou físico, da mesma forma, é reconhecível que o corpo que se instala no mundo, se expressa a partir de uma ordem de relações que a biologia e a fisiologia puras não suspeitam.
} 
Se nos apropriarmos da reflexão do filósofo, sobre como os gestos nos lançam novamente ao campo da expressão originária, veremos que foi nosso corpo, enquanto portador de comportamento, quem abriu no mundo, por meio do que Merleau-Ponty $(2004,1974)$ chama de gesto orientado, um campo inesgotável à nossa conduta. No caso da dança, o campo das significações dos gestos dançantes está aberto, desde que surgiu o ser-no-mundo e dançou; a chamada dança primitiva, ao nascer, iniciou um campo expressivo, fundando um espaço cultural, o qual longe de se esgotar nesse instante lançou-se num futuro aberto, um porvir de significações.

Como sugere Merleau-Ponty (1974), o primeiro gesto orientado inaugura uma ordem, funda uma instituição, uma tradição, que não se fecha, pois o ser, da mesma forma que dá vida aos primeiros gestos, neles se instala para deslizar dos signos aos sentidos, fazendo-os dizer novamente o que ainda não tinha sido proferido, de forma semelhante ao que ocorre na linguagem (fala falada, fala falante). Por isso, o filósofo assinala que a arte é composta por um esforço de dizer aquilo que permanece sempre a dizer. Com efeito, consideramos, então, que recomeços sempre estiveram presentes na dança. Dançando, partilhamos de um campo de significações comuns, porém, a partir dos nossos próprios gestos, desenhamos cavidades, relevos, proximidades, distâncias, engendramos sentidos, numa (des)construção devir. Dançar é uma forma de aventurar-se e "as aventuras não têm tempo, não têm princípio nem fim" (GUIMARÃES ROSA, 1965).

Esse é o advento anunciado por Merleau-Ponty, a obra coreográfica, e suas proposições artísticas ${ }^{5}$ ultrapassam seu tempo, e jamais se encerram nelas mesmas. Surge daí o não movimento, o excesso que nos convida a retomá-lo. É sobre rastros, traços e ecos que evocamos um dançar original. São os excessos, as destemperanças, que nos arrastam ao desassossego, dando-nos o que dançar.

A dança trabalha com essa circularidade, pontua Louppe (2012), o movimento é memória corporal, que assume duas formas complementares, o inscrito e o que se abre ao desconhecido na própria experiência, e tecendo-se a partir de uma natureza múltipla, cada clarão representa uma procura singular. Os movimentos percepcionados nos levam a uma incessante decifração que, por sua vez, retornam a um novo enigma. Temos aí uma expressão que nunca se completa, e só podemos concordar com Merleau-Ponty (2007) quando afirma: tudo que dizemos antecipa algo, e esse será retomado.

Não havendo coincidências, só há espaços para a diferença, portanto, a historicidade operante no universo da dança não nos deixa esquecer que nenhuma forma de expressar substituiu a outra, ao contrário, chocaram-se, imbricaram-se, distanciaram-se, somaram-se - recriando-se sob novas formas de se dizer.

Aqui reside um fato importante para pensarmos a dança como linguagem, a partir da fundamentação teórica de Merleau-Ponty. Quando o filósofo faz um paralelo entre as linguagens, não é para reduzir uma à outra, ou afirmar que a pintura significa

\footnotetext{
5 Fazem parte das proposições artísticas os métodos que auxiliam na construção da obra. Louppe (2012) destaca que o "trabalho da dança", composto pela poética do movimento, agrega procedimentos de composição (corporal/ teórico), e o que a autora faz é revisitar propostas estéticas, observando como o uso de ferramentas, métodos de aprendizagem, ideias estéticas [...], ultrapassam trabalhos corporais e obras coreográficas, entre eles: a exploração do fluxo, peso, espaço, diferentes partes do corpo, respiração, movimento abdicado de música [...].
} 
igualmente como as palavras. Ao contrário, todas as expressões falam ao seu modo; o esforço é apenas para situá-las dentro do tempo. Temporalidades que lhes são próprias e seguem descontinuadamente porque podem contar com entrecruzamentos perceptivos que nunca as deixam terminar. Para compreender a conexão entre tempo (historicidade), percepção (corpo-gesto) e expressão (dança), registramos alguns acontecimentos no processo de desenvolvimento e transformação da dança ao logo do tempo, já que é pelos entrecruzamentos perceptivos que a expressão nunca conhece o fim, nunca se completa, havendo sempre mais por dançar.

Nesse sentido, podemos observar como se entrelaçavam as danças populares e as danças de Corte. De acordo com Portinari (1989), durante séculos medievais que se estenderam também no Renascimento, as danças que nasciam das manifestações populares eram posteriormente adaptadas pela classe dominante. Executadas em recinto fechado, ganhavam um tom de refinamento e elegância, mas nem por isso podemos deixar de observar que foram recriadas ambas as manifestações, concomitantemente. O mesmo se pode dizer do balé de Corte que, nascendo das danças de corte, se transformou em balé teatral, chegando ao balé profissional.

$E$, mesmo após ser codificado ${ }^{6}$, o balé não deixou de ser repensado por seres que the foram concedendo outras possibilidades. A exemplo, podemos mencionar Georges Noverre $^{7}$ (1727-1810), que trouxe à dança clássica um espírito novo, propondo o balé de ação. Uma dança que se opôs ao mecanismo dos passos, emocionando, criando ilusão, e veiculando significados (MONTEIRO, 1998). Poderíamos citar também Diaghilev e Fokine ${ }^{8}$ com o desenvolvimento do balé moderno e tantos outros que lhe quiseram dar uma nova vida.

$\mathrm{Na}$ atualidade, essa transformação não parece cessar. Como evidencia Xavier (2012), o balé ainda se encontra vivo, reinventado em trabalhos contemporâneos de importantes coreógrafos, como nas criações de Édouard Lock (La La La Human Steps) e nas obras de Rodrigo Pederneiras (Grupo Corpo) ${ }^{9}$. Assinala a autora que, para ambos, o balé é um material a ser explorado e, ao misturar-se a outros elementos, aparece em cena transformado.

Ainda tratando da reinvenção da dança clássica, Xavier recorda do coreógrafo americano William Forsythe. Como nos mostra, esse coreógrafo entende o balé como uma língua viva, o que resulta em uma fala que não se diz da mesma forma. Contudo, chama-nos a atenção que, para ele, "o corpo é espaço potencial para dissolução de quaisquer fronteiras (a separação entre balé e outras danças, por exemplo)" (XAVIER, 2012, p. 54), e nessa perspectiva "[...] a dança é ato de inclusão no mundo, e não de desligamento. A dança é meio para evidenciar diferenças, para aprender a olhar" (XAVIER, 2012, p. 54-55). Isso, ao que tudo indica, tem um pouco

\footnotetext{
6 O balé clássico foi codificado, em 1700, por Pierre Beauchamp, professor da Academia de Luís XIV, que instituiu as cinco posições para essa dança, tendo como base a posição dos pés (endehors) e dos braços (port de bras).

7 Professor e bailarino de balé francês. Foi responsável pela modificação de movimentos convencionais da dança clássica. Propôs o abandono de vestimentas pesadas e luxuosas, assim como das perucas, para devolver ao corpo a sua expressividade (GARAUDY, 1980).

8 Serge Diaghilev (1872-1929) empresário russo que fundou, organizou e dirigiu os Ballets Russes - Michel Fokine (1880-1942) coreógrafo e bailarino russo. Trabalhando juntos, foram responsáveis por muitas mudanças no balé clássico, como: figurinos, temas, tempo de duração de espetáculos, movimentação dos bailarinos e outros mais.

9 Grupo Corpo, fundado em 1975, Belo Horizonte, Brasil. La La La Human Steps, formada em 1980, Montreal, Canadá
} 
do que Merleau-Ponty nos diz quando destaca uma historicidade que não exclui, e um corpo que possui a capacidade de transpor distâncias, escavando, desvendando o futuro perceptivo, que muito devemos à disposição e à abertura de nosso olhar ${ }^{10}$.

Assim,

[...] admitimos que o próprio do gesto humano é significar além de sua simples existência de fato, inaugurar um sentido, resulta disso que todo gesto é comparável a todo outro, que provenha todos de uma só sintaxe, que cada deles seja um começo, comporte uma seqüência ou recomeços enquanto não é, como o acontecimento, opaco e fechado sobre si mesmo [...] MERLEAU-PONTY,1974, p. 91).

Se considerarmos que o próprio da cultura é nunca começar e não acabar no instante (MERLEAU-PONTY, 1974), conferimos que não há criação que se sustente apenas do ponto de vista natural. Diante disso, destacamos Isadora Duncan (18771927), dançarina americana, considerada um dos marcos da modernidade na dança.

Segundo Dantas $(1999,2005)$, desde o seu surgimento no início do século $\mathrm{XX}$, a dança moderna teve como um dos seus principais objetivos expressar as inquietações e contradições do seu tempo. Nesse período surgiram outras maneiras de compreender o corpo e a dança, que resultaram em outras formas de fazer. Assim, "sem estabelecer um sistema universal de criação, interpretação e ensino em dança, como no caso do balé, a dança moderna estruturou-se a partir de diferentes métodos, instaurando diferentes poéticas" (DANTAS, 2005, p.33).

Ainda, segundo a autora, um aspecto que permeou os projetos de dançarinos e coreógrafos modernos foi a busca pelo "corpo natural", motivação e inspiração que se concretizou em novas formas coreográficas. No entanto, ao elaborar uma proposta artística que almejava a libertação de códigos rígidos, Isadora Duncan acaba por vezes criando a falsa ideia de que seu projeto escapou de um trabalho corporal técnico. É preciso pontuar que Duncan não apenas refletiu intensamente sobre sua arte, mas também estudou o movimento e dedicou-se à leitura de obras e escritos sobre dança, bem como de autores como Jean-Jacques Rousseau, Walt Whitman e Nietzsche (DANTAS, 2007).

Aqui, evidenciamos que há no campo da dança, sem dúvida, experiências singulares, o que impulsiona um sentido, antes de tudo, em gênese. Porém, essa situação não indica que a obra nasça de um monólogo interior. Isadora, estudando imagens de gestos dançados nos vasos gregos, situados no museu do Louvre na França, também se inspirou neles, evocando todo o campo de significação carregado naqueles gestos, o que resultou na sua própria criação. Em uma passagem de sua autobiografia, a dançarina cita um discurso que recebeu de um pintor que apreciava sua arte e que entre tantas palavras dizia:

Isadora, no seu desejo de exprimir os sentimentos humanos, achou na arte grega os mais belos modelos. [...] dotada do instinto das descobertas, ela voltou-se para a natureza, origem de todos esses movimentos e, convencida de que é preciso imitar e revivificar a dança grega achou a sua própria expressão. [...] A dança de Isadora não é um divertimento, é uma manifestação pessoal, uma obra de arte viva, que nos incita a trabalhar e

10 Não no sentido apenas da visão dos olhos, posto que para Merleau-Ponty podemos olhar com o corpo por inteiro, nossas mãos podem ver, nossos olhos podem tocar, e assim por diante, há sempre imbricamento dos sentidos. 
fecunda dentro de nós as obras a que o destino nos chamou e que ainda haveremos de realizar (CARRIÈRE apud DUNCAN 1969, p. 65-66).

Aí reside o sentido do advento anunciado por Merleau-Ponty que é, sobretudo, promessa de eventos. No devir dançante moderno, após a criação dessa "nova dança", outros vieram, como: Martha Graham, Ruth St. Denis e Ted Shawn, Rudolf Von Laban, Mary Wigman, Doris Humphrey ${ }^{11}$, entre outros que, dando continuidade, trouxeram novas propostas estéticas, criando técnicas, métodos, surgindo outros estilos dançantes, e esses continuam na atualidade inspirando novas obras que nunca param de nascer, reunindo-se em novas tentativas de expressão. Nessa direção, Dantas (1999) ressalta que técnicas de movimentos - incluindo as consagradas são resultado de todo um processo em que estão acumuladas tradições e inovações, concepções que recebem sempre influências de um contexto, e podem ser desdobradas, continuadas ou reinterpretadas.

Louppe (2012), ao se ater a esse processo de transformação no campo da dança, anuncia fronteiras flutuantes e, com isso, assume não mais uma distinção entre a modernidade e a contemporaneidade nessa arte ${ }^{12}$. Recorrendo às escolas, coreógrafos e bailarinos, a autora investiga uma "herança dialética em que cada contributo é novamente posto em causa, retomado, deslocado, rejeitado, por vezes eliminado, revisitado e, por fim, aperfeiçoado de forma inesperada" (p. 43). Para a autora, só existe uma dança contemporânea que nasce no início do século XX e desde então carrega a ideia de uma linguagem gestual não transmitida. É possível reencontrar, na poética da dança contemporânea, o que Louppe chama de os mesmos valores, que sofrem abordagens por vezes opostas, mas sempre reconhecíveis, entre eles, a individualização de um corpo e de um gesto sem modelo, que busca uma identidade, a produção no lugar da reprodução de um gesto ${ }^{13}$. Contudo, o que interessa à autora é descrever o entrecruzamento de percepções e alianças súbitas entre os corpos que, por vezes, nunca se encontraram.

Podemos pensar que essa força latente, destacada por Louppe, que ultrapassa o universo contemporâneo da dança, de alguma forma se relaciona com os questionamentos de Merleau-Ponty a respeito do suposto rompimento entre a pintura clássica e a moderna. Assim como a autora reivindica um tempo não cronológico entre a modernidade e a contemporaneidade da dança, o filósofo é ainda mais radical quando ressalva que não se pode escolher ou separar o mundo e a arte, nossos sentidos e a pintura, estão todos entrelaçados (MERLEAU-PONTY, 2004).

\footnotetext{
11 Bailarinos, coreógrafos e professores de grande destaque que impulsionaram a dança moderna: Martha Graham (1894-1991): bailarina, coreógrafa e professora norte-americana. Ruth St. Denis(1879-1968): bailarina, coreógrafa e professora norte-americana. Ted Shawn (1891-1972): bailarino, coreógrafo e professor norte-americano, casouse com Ruth St. Denis e fundaram a escola Denishawn (1915-1931) com sede em Los Angeles. Rudolf Von Laban (1879-1958) húngaro, bailarino, coreógrafo, professor e um dos grandes teóricos da dança. Mary Wigman (18861973): bailarina, coreógrafa e professora alemã. Doris Humphrey (1895-1958): bailarina, coreógrafa e professora norte-americana.

12 Louppe assinala que a contemporaneidade na dança começa com Isadora Duncan, porém traz outros nomes, como François Delsarte, por exemplo.

13 Exemplificando valores que ultrapassam o tempo, Louppe menciona que "é surpreendente ver, por exemplo, como o entusiasmo actual dos bailarinos europeus por Trisha Brown operou uma retomada dos valores essenciais da dança contemporânea, nos quais nem sempre se pensava: a experiência do peso, a fluidez de um movimento contínuo, a imprevisibilidade de um gesto futuro, etc." (p. 43).
} 
Vemos que Merleau-Ponty retomando as análises de Malraux, sobre a pintura clássica como representação da natureza, e a pintura moderna como questionadora dessa objetividade, conclui que são necessárias revisões, uma vez que a ideia de expressão criadora é, sem dúvida, moderna, mas cumpre-nos interrogar: - Será que por isso podemos considerar a pintura clássica apenas como representação de uma natureza?

Nesse contexto, Merleau-Ponty (1974, p. 64) nos conta que

[...] Malraux indica freqüentemente que a concepção moderna da pintura, como expressão criadora, foi uma novidade para o público muito mais que para os próprios pintores, que sempre a praticaram, mesmo se não tinham consciência dela e não faziam sua teoria, que, por essa razão mesma, freqüentemente anteciparam a pintura que nós praticamos $[\ldots]$.

Com isso, elucida o filósofo francês que a pintura clássica não consiste apenas em representar, não é exercício arbitrário; resta-nos, então, reconhecê-la "[...] como uma criação, e isto, no próprio momento em que quer ser representação de uma realidade" (1974, p. 67), posto que os clássicos, muitas vezes, operavam sem saber tal metamorfose. Os gestos, sendo sustentados pela experiência corporal, tendem a ultrapassar e a escapar de qualquer objetividade, e aí reside o apreço de MerleauPonty pela aproximação das artes e da linguagem; da mesma forma em que a arte clássica não consiste apenas na representação do mundo, no decalque da cultura, e a arte moderna não se reduz ao reduto individual da criação, nossas palavras não possuem o papel de reencontrar a expressão já antecipada e muito menos se dão fora da coexistência. Arte e linguagem nunca acabam no que dizem, suscitam na própria expressão uma busca, cujos sentidos não acabamos de alargar.

Emprestando as palavras de Merleau-Ponty (2004), com toda razão, podemos afirmar que a dança moderna, ou contemporânea de Isadora Duncan, não é uma volta à subjetividade. Como já presenciamos, não houve uma vida secreta fora do mundo, pelo contrário foi imitando e revivificando a dança grega que encontrou sua própria expressão, seu estilo. Da mesma forma, se trilhamos o pensamento do filósofo, é necessário um esforço para a desconstrução da ideia comum do balé clássico, que aparece, muitas vezes, apenas como uma técnica que privilegia a pura imitação. Não se trata de negar que existam métodos de treinamento nessa dança que almejam encontrar a perfeição, a estabilidade dos gestos, porém a dimensão da experiência corporal descrita por Merleau-Ponty quer nos mostrar o corpo como um nó de significações vivas, que não se fixa em situação alguma, o que nos permite no instante da ação, re-convocar a expressão novamente.

Com esse fato, constatamos em nós humanos o poder de ultrapassamento, potência instituinte, que tende a tornar as artes e a linguagem sempre expressivas a cada vez. Esse é o poder da nossa percepção encarnada, visto que "a percepção nos abre a um mundo já constituído, e só pode reconstituí-lo” (MERLEAU-PONTY, 1974, p. 134).

É pela experiência perceptiva que a dança se refaz única, mas é também por ela que a dança se vê ultrapassada e contaminada por outras percepções. Trata-se de uma percepção que não só abre o tempo, mas se dá como tempo, ganhando vida, via expressão. 
Nessa direção, elucida Nunes $(2011 ; 2008)$ que a percepção é movimento. Percepção simula a ação e a ação organiza a percepção, "a percepção é ativa, e é ela que nos permite experienciar a nós mesmos e ao entorno no presente, a partir de uma compreensão do passado e um direcionamento para a ação futura" (NUNES, 2011, p.2). Por isso, "a percepção se renova para conseguir novos gestos e definir formas inovadoras de presença” (PITOZZI, 2014, p. 177).

Isso é o que possibilita dois gestos culturais nunca se tornarem idênticos, tornando impossível em arte a pura e simples repetição (MERLEAU-PONTY, 1974). Como vemos em Bardet (2014, p.169), "aprender é ao mesmo tempo perceber e agir, em um gesto que partilha a percepção com a ação". E é por esse viés que a dança, como todas as artes, seja ela clássica, popular, moderna, contemporânea (...), tornase possível como um horizonte aberto, para novas percepções, novas construções, novas relações, novas dimensões, novas significações.

Temos a impressão de que Forsythe está de acordo com Merleau-Ponty, quando diz "[...] a dança é ato de inclusão no mundo, e não de desligamento" (XAVIER, 2012, p. 54-55). Talvez, se Merleau-Ponty estivesse vivo, continuasse a sustentar um tempo alargado entre a arte clássica, moderna e contemporânea. $\mathrm{Na}$ perspectiva pontyana, poderíamos pensar que não existem fronteiras fixas entre as formas de dançar; o que há são as diferenças, campos e campos expressivos, e as assinaturas pessoais (estilos), mas nunca a exclusão. A dança moderna para nascer necessitou da existência da dança clássica para desejar tornar-se diferente.

Os projetos mudaram, mas não a tarefa, tentativa de expressão, deformação coerente. Valendo-nos das reflexões de Merleau-Ponty (2004, p. 91), vemos que "todos os tempos pertencem a um mesmo universo", e o clássico e o moderno, ou o clássico e o contemporâneo pertencem ao universo da dança. Nossa tarefa está aberta desde que surgiu o primeiro gesto dançante (primitivo/cerimonial) até a nossa dança "consciente".

Aí temos a prosa do mundo, logo a prosa da dança, a prosa dos sentidos, a prosa das percepções (...) emaranhadas, incessantemente, ao inacabamento. É a emergência da expressão, nascendo do ser selvagem, e simultaneamente, contando com a singularidade, de alguma maneira, tocada pela pluralidade.

Se considerarmos a dança nessa perspectiva - ser-no-mundo - vemos que ao deixar cair os adjetivos que seguem de mãos dadas com ela: dança'jazz', dança'flamenca', dança-'contemporânea', dança-'clássica', dança'popular'.., a dança permanece. Apesar das infindáveis diferenças, há algo que nos faz reconhecer, talvez, a energia viva presente no gesto humano, pulsão de vida e a busca pela expressão, que não cessa em lugar algum, operando descontinuamente, sempre quando alguém se põe a dançar. Mas nossa tendência, com toda a grandeza de viver, é sempre agregar mais e mais características, aumentando o campo expressivo, operando pela diferença, porque ser, nos diz Merleau-Ponty (2007), é o que de nós exige criação, para que dele tenhamos a experiência. 


\section{CONSIDERAÇÕES FINAIS}

A dança nasce da experiência perceptiva. O dançarino esboça na percepção os primeiros sinais da dança. É a potência expressiva atada sempre a um horizonte perceptivo, capaz de retomar um gesto, transformá-lo e continuá-lo para além do visto, do dito e do dançado. Entender esses cruzamentos de tempos e espaços libertados de cronologias e fronteiras no campo da dança requer admitir, com Louppe (2012, p. 369), outro tipo de memória, "uma memória do devir, um continuum da prática corporal, reinventando-se a cada instante na presença do presente que une os corpos pelas convulsões da história".

Essa é a história viva que, segundo Merleau-Ponty, permite uma ordem geral do advento. Advento é sempre promessa de acontecimento. Entende-se que a obra, ou um repertório de gestos, nunca se fecha em sua diferença, comporta sempre recomeços, inaugura um sentido, ao mesmo instante em que significa para além de sua existência. $O$ ir além da existência nos mostra, de fato, o quanto não temos o controle quando uma dança vem ao mundo. Como será sua repercussão? O que ela despertará ou perturbará no outro? Não há certezas. Com efeito, abre-se um campo de pesquisas que, nas palavras de Merleau-Ponty, é de antemão, cúmplice de todas as demais tentativas de expressão. Por esse motivo, a história vive do inacabamento provocado pelo entrelaçamento da percepção que dá vida a expressão.

Merleau-Ponty nos faz compreender a potência da expressão encarnada, linguagem temporalizada, experienciada, que opera não como continuidade, no sentido arbitrário causa e efeito, pela qual pudéssemos explicar de onde vem cada gesto, mas que atua justamente na complexidade do trabalho perceptivo, que inaugura o recomeço pela diferença: "é a operação expressiva do corpo, iniciada pela menor percepção que se amplifica em arte” (MERLEAU-PONTY, 2004). Apesar de gestos compactuarem de uma mesma temporalidade, acenam para a multiplicidade, onde a sequência é recomeço. Os diferentes estilos dançantes nascem dos entrecruzamentos perceptivos; é pelos diálogos que a expressão nunca conhece o fim, nunca se completa, havendo sempre mais por dançar.

\section{REFERÊNCIAS}

BARDET, Marie. A filosofia da dança: um encontro entre dança e filosofia. São Paulo: Martins Fontes, 2014.

BERNARD, Michel. Sens et fiction : ou les effets étranges de trois chiasmes sensoriels. In :BERNARD, Michel. De la création chorégraphique. Paris: Centre National de la Danse, 2001.

DANTAS, Mônica Fagundes. Dança: o enigma do movimento. Porto Alegre: Editora da UFRGS, 1999.

DANTAS, Mônica Fagundes. O corpo natural de Isadora Duncan e o natural no corpo em educação somática: apontamentos para uma história do "corpo natural" em dança. In: GOELLNER, Silvana Vilodre; JAEGER, Angelina Alice (org.). Garimpando memórias: esporte, educação física, lazer e dança. Porto Alegre: Editora da UFRGS, 2007. p. 149-161. 
DANTAS, Mônica Fagundes. De que são feitos os dançarinos de "aquilo..." criação coreográfica e formação de intérpretes em dança contemporânea. Movimento, v. 11, n. 2 , p. 31-57, maio/ago. 2005. Disponível em: https://www.lume.ufrgs.br/handle/10183/20023. Acesso em: 18 nov. 2020.

DUNCAN, Isadora. Minha Vida. 8. ed. Rio de Janeiro: José Olímpio, 1969.

FAZENDA, Maria José. A dança como visão do mudo: da grande modernidade à época actual. In: LOUPPE, Laurence. Poética da dança contemporânea. Lisboa: Orfeu Negro, 2012.

FENSTERSEIFER, Paulo Evaldo. Corpo e Linguagem. In: STREY, Marlene N.; CABEDA, Sonia L. (org.). Corpos e subjetividades em exercício interdisciplinar. Porto Alegre: EDIPUCRS, 2004. p.289-301.

FENSTERSEIFER, Paulo Evaldo; PICH, Santiago. Ontologia pós-metafísica e o movimento humano como linguagem. Impulso, v. 22, n. 53, p. 25-36, 2012. DOI: https://doi. org/10.15600/2236-9767/impulso.v22n53p25-36. Disponível em: https://www.metodista.br/ revistas/revistas-unimep/index.php/impulso/index. Acesso em: 12 dez. 2020.

GADAMER, Hans-Georg. Verdade e método I: traços fundamentais de uma hermenêutica filosófica. 12. ed. Petrópolis: Vozes, 2012.

GARAUDY, Roger. Dançar a vida. 7. ed. Rio de Janeiro: Nova Fronteira, 1980.

GIL, José. Movimento Total: o corpo e a dança. 2. ed. São Paulo: lluminuras, 2004.

GODARD, Hubert. Gesto e percepção. In: SOTER, Silvia; PEREIRA, Roberto. (org.). Lições de Dança 3. Rio de Janeiro: UniverCidade, 2001. p. 11-35.

GUIMARÃES ROSA, João. Grandes entrevistas. Entrevistador: Gunter Lorenz. Tiro de letra, c2007. Disponível em: http://www.tirodeletra.com.br/entrevistas/GuimaraesRosa-1965. htm . Acesso em: 12 dez. 2020.

LOUPPE, Laurence. Poética da dança contemporânea. Lisboa: Orfeu Negro, 2012.

MATTHEWS, Eric. Compreender Merleau-Ponty. Petrópolis: Vozes, 2010.

MERLEAU-PONTY, Maurice. O visível e o invisível. São Paulo: Perspectiva, 2007.

MERLEAU-PONTY, Maurice. $O$ olho e o espírito: seguido de A linguagem indireta e as vozes do silêncio e A dúvida de Cézanne. Tradução de Paulo Neves e Maria E. G. G. Pereira. São Paulo: Cosac \& Naify, 2004.

MERLEAU-PONTY, Maurice. Fenomenologia da Percepção. Tradução de Carlos A. R. Moura. 2. ed. São Paulo: Martins Fontes, 1999.

MERLEAU-PONTY, Maurice. Signos. Tradução de Maria E. G. G. Pereira. São Paulo: Martins Fontes, 1991.

MERLEAU-PONTY, Maurice. $O$ homem e a comunicação: a prosa do mundo. Tradução de Celina Luz. Rio de Janeiro: Bloch, 1974.

MONTEIRO, Marianna. Noverre: cartas sobre a dança. São Paulo, Edusp/Fapesp, 1998

NUNES, Sandra Meyer. Presença: entre Percepção e Ação. In: VI Reunião Científica de Pesquisa e Pós-Graduação em Artes Cênicas, 2011, Porto Alegre. Anais ABRACE. v. 12, n. 1, 2011. Disponível em: https://www.publionline.iar.unicamp.br/index.php/abrace/article/ view/3174/3337. Acesso em: 21 nov. 2020. 
NUNES, Sandra Meyer. Pontos de vista sobre percepção e ação no treinamento do ator: Viewpoints em questão. DAPesquisa, v.3 n.5, p.1227-1238, 2008. DOI: https://doi.org/1 0.5965/18083129030520081227. Disponível em:https://www.revistas.udesc.br/index.php/ dapesquisa/article/view/15849. Acesso em: 20 nov. 2020.

PITOZZI, Enrico. A Percepção é um Prisma: corpo, presença e tecnologias. Revista Brasileira de Estudos da Presença, v. 4, n. 2, p. 174-204, 2014. DOI: https://doi. org/10.1590/2237-266043367. Disponível em: https:/www.scielo.br/scielo.php?script=sci arttext\&pid=S2237-26602014000200174\&lng=en\&tlng=en. Acesso em: 12 dez. 2020.

PORTINARI, Maribel. História da Dança. Rio de Janeiro: Nova Fronteira, 1989.

XAVIER, Jussara Janning. Acontecimentos de dança: corporeidades e teatralidades contemporâneas. Tese (Doutorado em Teatro - Área: Teorias e Práticas Teatrais) Universidade do Estado de Santa Catarina. Programa de pós-graduação em Teatro, Florianópolis, 2012. 
Abstract: In the light of Merleau-Ponty's philosophical reflections, this essay aims to understand dance as a language. Based on the correlation among perception, historicity and expression, the philosopher envisages closeness between art and language. To better understand how these three elements connect, we situate some events in the process of development of dance over time, presenting works by modern and contemporary dance artists. It is a crucial condition for realizing that dance never ceases to change. This proposition enables us to understand how expressions are not unconnected to time and feed on their own mobility. It is through perceptual intersections that expression never ends, it is never completed, there is always more to be danced. Opening up to language as the realization of meaning and world experience is crucial for thinking about possibilities of experiencing dance as language.

Keywords: Dancing. Language. Philosophy. Perception.

Resumen: Este ensayo, a la luz de las reflexiones filosóficas de Merleau-Ponty, tiene como objetivo comprender la danza como lenguaje. Es a partir de la correlación entre percepción, historicidad y expresión que el filósofo visualiza proximidad entre arte y lenguaje. Para comprender la conexión entre estos tres elementos, situamos algunos hechos en el proceso de desarrollo de la danza a lo largo del tiempo, trayendo obras de artistas de la danza moderna y contemporánea. Es una condición importante para que nos demos cuenta de que la danza nunca deja de transformarse. Tal proposición hace que entendamos que las expresiones no son ajenas al tiempo y se alimentan de sus propias movilidades. Es a través de los entrecruzamientos perceptivos que la expresión nunca conoce el fin, nunca se completa, quedando siempre más por danzar. Abrirse al lenguaje como realización de sentido, experiencia de mundo, es fundamental para que pensemos posibilidades de la experiencia de la danza como lenguaje.

Palabras clave: Palabras clave: Danza. Lenguaje. Filosofía. Percepción. 


\section{LICENÇA DE USO}

Este é um artigo publicado em acesso aberto (Open Access) sob a licença Creative Commons Atribuição 4.0 Internacional (CC BY 4.0), que permite uso, distribuição e reprodução em qualquer meio, desde que o trabalho original seja corretamente citado. Mais informações em: http://creativecommons.org/licenses/by/4.0

\section{CONFLITO DE INTERESSES}

Os autores declararam que não há conflito de interesses neste trabalho.

\section{CONTRIBUIÇÕES AUTORAIS}

Danieli Alves Pereira Marques: A pesquisa faz parte da tese de doutorado da primeira autora orientada pelo segundo autor. Redação.

Elenor Kunz: Orientação e revisão da pesquisa.

\section{FINANCIAMENTO}

O presente trabalho foi realizado com apoio da Coordenação de Aperfeiçoamento de Pessoal de Nível Superior -Brasil (CAPES) - Código de Financiamento 001 This study was financed in part by the Coordenação de Aperfeiçoamento de Pessoal de Nível Superior - Brasil (CAPES) - Finance Code 001.

\section{COMO REFERENCIAR}

MARQUES, Danieli Alves Pereira; KUNZ, Elenor. Dança: entre percepção, historicidade e expressão: a dança como linguagem. Movimento (Porto Alegre), v.26, p.e26096, jan./dez. 2020. Disponível em: https://seer.ufrgs.br/Movimento/ article/view/103309. Acesso em: [dia] [mês abreviado]. [ano]. DOI: https://doi. org/10.22456/1982-8918.103309

\section{RESPONSABILIBADE EDITORIAL}

Alex Branco Fraga*, Elisandro Schultz Wittizorecki*, Ivone Job*, Mauro Myskiw*, Raquel da Silveira*

*Universidade Federal do Rio Grande do Sul, Escola de Educação Física, Fisioterapia e Dança, Porto Alegre, RS, Brasil 